\title{
Acute Appendicitis Following Laparoscopic Hysterectomy
}

\author{
Fariba Almassinokiani ${ }^{1,2}$, Mohammadali Ghoraian ${ }^{1}$, Hossein Akbari ${ }^{1}$, Alireza Almasi ${ }^{1,3^{*}}$, Ab- \\ dolreza Pazouki ${ }^{1}$, Mohammadkazem Shahmoradi ${ }^{1}$, Mahboubeh Saberifard ${ }^{1}$ \\ ${ }^{1}$ Minimally Invasive Surgery Research Center, Rasool Akram Hospital, Tehran University of Medical Sciences, Tehran, IR Iran \\ 2 Department of Gynecology and Obstetrics, Rasool Akram Hospital, Tehran University of Medical Sciences, Tehran, IR Iran \\ ${ }^{3}$ Department of Radiology, Firoozgar Hospital, Tehran University of Medical Sciences, Tehran, IR Iran
}

A R T I C L E I N F O

Article type:

Case report

Article history:

Received: 26 Sep 2011

Revised: 17 Jan 2012

Accepted:14 Feb 2012

\begin{abstract}
A B S T R A C T
Appendicitis after age 40 is unusual, and appendicitis two days after laparoscopic hys terectomy is very rare and has not been reported to date. We describe a 44-year-old woman who had abdominal pain two days after laparoscopic hysterectomy. The pathology report indicated early appendicitis and the pain disappeared after appendectomy. In our opinion, the cause of appendicitis may have been related to the use of monopolar and bipolar coagulation during laparoscopic hysterectomy, although the coincidence of appendicitis and laparoscopic surgery may be accidental.
\end{abstract}

Keywords:

Appendicitis

Electrosurgery

Hysterectomy

Laparoscopy

- Implication for health policy/practice/research/medical education:

This article focused on cautions for laparoscopic surgeons to have attention to bowel injuries including appendicitis. Laparoscopic surgeons, gynecologists are recommended to study this article.

Please cite this paper as:

Almassinokiani F, Ghoraian M, Akbari H, Almasi A, Pazouki A, Shahmoradi M, et al. Acute Appendicitis Following Laparoscopic Hysterectomy. J Minim Invasive Surg Sci. 2012;1(2): 74-6. DOI: 10.5812/ jmiss.2289

\section{Introduction}

Laparoscopic surgeries are a very new technique. Every day our knowledge increases regarding laparoscopic surgery with minimal complications, and one way to reduce complications is by reading about the experiences of other surgeons. In a 1993 survey of the American Association of Gynecologic Laparoscopists (AAGL), the rate of bowel or urinary injuries in operative laparoscopy in 45,042 procedures was $0.41 \%(1)$. In another study, the rate of major complications in gynecologic operative laparoscopies

\footnotetext{
* Corresponding author: Alireza Almasi, Department of Radiology, Firoozgar Hospital, Tehran University of Medical Sciences, Tehran, IR Iran Tel: +989123100639, Fax:+98-2166509283, E-mail: dralmassi@yahoo.com

DOI: $10.5812 /$ jmiss.2289

Copyright (C) 2012, Minimally Invasive Surgery Research Center and Mediterranean \& Middle Eastern Endoscopic Surgery Association. This is an open-acces article distributed under the terms of the Creative Commons Attribution License, which permits unrestricted use, distribution, and reproduction in any medium, provided the original work is properly cited.
}

among 843 operations was $1.9 \%$, with 4 bowel injuries (2). In a retrospective review of over 600,000 operative laparoscopies with closed techniques for establishment of pneumoperitoneum, the rate of bowel injury was $0.083 \%$. In a survey of 4,307 operative gynecologic laparoscopies, the major complication rate was $1.66 \%(n=2174)$ in the LAVH (Laparoscopic Assisted Vaginal Hysterectomy) group (3). None of these surveys reported appendicitis as a bowel complication following laparoscopic surgery.

\section{Case Presentation}

A 44-year-old woman was a candidate for total laparoscopic hysterectomy, because of abnormal uterine bleeding and mild dysplasia of the cervix with onset two years earlier. She had a history of two vaginal births and had no 
significant antecedent in her medical history. Her weight was $65 \mathrm{~kg}$. Before laparoscopy, informed consent was obtained from the patient regarding the risks and complications of the laparoscopic procedure and the possibility of switching to laparotomy if the procedure could not be completed via the laparoscopic route. Under general anesthesia, with endotracheal intubation, we used two sharp, curved towel clamps to grasp the skin and elevate the abdominal wall at the site of initial entry, and did not employ a Veress needle. We used one $12-\mathrm{mm}$ port in the umbilicus (closed entry) and three $5-\mathrm{mm}$ ports in the left lower quadrant, right lower quadrant and suprapubic region. At the dorsal lithotomy position after insertion of the primary trocar, the pneumoperitoneum was established with carbon dioxide, and intra-abdominal pressure was around $15 \mathrm{mmHg}$. In the laparoscopic hysterectomy, the round ligament and ovarian and uterine vessels were dissected by bipolar forceps (Storz), cut with scissors, and the ovaries reserved. We used a Storz uterine manipulator to carry the cervix up away from the bladder, bowel and ureters. The cardinal ligament hemostasis and anterior and posterior colpotomy were performed laparoscopically with monopolar electrical current at 80 W power. All surgical procedures were performed using bipolar and monopolar coagulation. After the uterus was removed, the colpotomy was sutured vaginally with Vicryl 0 sutures and all trocar ports were repaired. For the 5-mm ports, skin was repaired, and for the $12-\mathrm{mm}$ port, fascia and skin were repaired. The first day after the operation, the gynecologic surgeon visited the patient. The patient's vital signs were normal. She was hungry and began a liquid diet. The next day, the patient's vital signs were normal and she had mild generalized tenderness in the abdomen. Consultation with a general surgeon was requested. An abdominal CT scan with IV and oral contrast was performed (for probability of thermal injury to the gastrointestinal or urinary tract). CT scan was normal. On a serial CBC, hemoglobin was normal and WBC rose from 9,000 to 11,000 per mL. The patient was under close observation with serial abdominal examinations and $\mathrm{CBC}$ tests, and oral intake was discontinued. The following day (third day after the operation), the generalized abdominal pain and tenderness increased and her appetite decreased, but her general situation was good and her vital signs were normal. We decided to perform a diagnostic laparoscopy, but the patient refused and chose laparotomy for the next step. We performed a minilaparotomy with midline incision and explored all of her abdomen. There was no blood or free fluid in the abdomen. The liver, spleen, stomach and intestine were normal, but the appendix was inflamed and we performed an appendectomy. The pathology report indicated early appendicitis and periappendicitis. The day after the appendectomy, the patient's vital signs were normal and her abdominal pain disappeared. We initiated a liquid diet and she was discharged the next day.

\section{Discussion}

For over 15 years, total laparoscopic hysterectomy (TLH) and laparoscopic supracervical hysterectomy (LSH) have been performed by pioneer surgeons around the world, and their complication rate in comparison with total abdominal hysterectomy (TAH) is not high. The rate of bowel injury in various surveys ranges from $0.16 \%(3,4)$ to $0.33 \%$ (5) and $0.62 \%$ (1). In one meta-analysis of 29 studies, the overall bowel injury rate was $0.13 \%$ (6). In one study on $108 \mathrm{TLH}, 251 \mathrm{LSH}$ and $255 \mathrm{TAH}$, the rate of major complications was $17.6 \%$ with TLH, $16.7 \%$ with LSH and $14.1 \%$ with TAH. The rate of readmission was $6 \%$ with TLH, $3 \%$ with LSH and 5\% with TAH. In these 359 laparoscopic hysterectomies (LH), the rate of bowel injury was $0 \%$, but there was one case of readmission due to appendicitis and there were no explanations for it (7). In one survey on complications of laparoscopic surgery for benign ovarian cysts in 513 women, major complications occurred in 3 patients ( $0.6 \%$ ) with one bowel injury (8). The incidence of complications related to laparoscopic electrosurgery has been reported to be 2.3 per 1000 electrosurgical procedures in the 1970 s and $2-5$ per 1000 in the 1990 s. In 1997 , a bowel injury rate of 4 per 1000 in LAVH was reported $(9,10)$. Most electrosurgical injuries to the bowel (approximately $75 \%$ ) are unrecognized at the time of occurrence. The result of unrecognized bowel injury is usually serious. The small bowel, in particular the ileum, is most frequently involved. Symptoms of bowel perforation following electrosurgical injury are usually seen 4-10 days after the procedure. With direct traumatic perforation, symptoms usually occur within 12-36 hours. During the postoperative observation period, which may last 3-5 days, the laparoscopist should be highly alert to early manifestations of peritonitis. Abnormal laboratory and imaging tests are helpful in confirming the diagnosis, although normal test results do not necessarily rule out complications. Increased abdominal pain after laparoscopic surgery sometimes requires a repeat laparoscopy with a negative finding (11).

\section{Conclusions}

In patients with abdominal pain after operative laparoscopy with monopolar or bipolar coagulation, we should bear in mind the probability of thermal bowel injury as a complication of electrosurgery. In this case we do not have strong evidence that electrosurgery was the cause of appendicitis, but it could be the culprit. The coincidence of electrosurgery and appendicitis makes it probable that the cause of appendicitis was electrocoagulation.

\section{Acknowledgment}

We would like to appreciate Dr. S. Mokhber, Dr. Z. Taman- 
naie, and Ms. Pishgah for their kind cooperation.

\section{Authors' Contribution}

$50 \%$ first author, $40 \%$ corresponding author and 10\% other authors.

\section{Financial Disclosure}

None declared.

\section{Funding/Support}

This article is supported by Minimally Invasive Surgery Research Center, Rasool Akram Hospital, Tehran University of Medical Sciences, Tehran, Iran.

\section{References}

1. Hulka J, Peterson HB, Phillips JM, Surrey MW. Operative laparoscopy: American Association of Gynecologic Laparoscopists' 1993 membership survey. J Am Assoc Gynecol Laparosc. 1995;2(2):133-6.

2. Mirhashemi R, Harlow BL, Ginsburg ES, Signorello LB, Berkowitz R, Feldman S. Predicting risk of complications with gynecologic laparoscopic surgery. Obstet Gynecol.1998;92(3):327-31.

3. Tian YF, Lin YS, Lu CL, Chia CC, Huang KF, Shih TY, et al. Major complications of operative gynecologic laparoscopy in southern Taiwan: a follow-up study.J Minim Invasive Gynecol. 2007;14(3):284-92.

4. Harkki-Siren P, Sjoberg J, Kurki T. Major complications of laparoscopy: a follow-up Finnish study. Obstet Gynecol.1999;94(1):94-8.

5. Wu MP, Lin YS, Chou CY. Major complications of operative gynecologic laparoscopy in southern Taiwan. J Am Assoc Gynecol Laparosc. 2001;8(1):61-7.

6. van der Voort M, Heijnsdijk EA, Gouma DJ. Bowel injury as a complication of laparoscopy. BrJ Surg. 2004;91(10):1253-8.

7. Hoffman CP, Kennedy J, Borschel L, Burchette R, Kidd A. Laparoscopic hysterectomy: the Kaiser Permanente San Diego experience. J Minim Invasive Gynecol. 2005;12(1):16-24.

8. Lok IH, Sahota DS, Rogers MS, Yuen PM. Complications of laparoscopic surgery for benign ovarian cysts. J Am Assoc Gynecol Laparosc. 2000;7(4):529-34.

9. Wu MP, Ou CS, Chen SL, Yen EY, Rowbotham R. Complications and recommended practices for electrosurgery in laparoscopy. Am J Surg. 2000;179(1):67-73.

10. Shirk GJ, Johns A, Redwine DB. Complications of laparoscopic surgery: How to avoid them and how to repair them.J Minim Invasive Gynecol. 2006;13(4):352-9; quiz 60-1.

11. O'Hanlan KA, Fisher DT, O'Holleran MS. 257 incidental appendectomies during total laparoscopic hysterectomy. JSLS. 2007;11(4):428-31. 